\title{
Sonographic Incidence and Characteristics of Thyroid Nodules in Various Age Groups and Gender
}

\author{
Rabia Parveen ${ }^{1}$, Dr Raham Bacha ${ }^{1}, \mathrm{~S}$ Muhammad Yousaf Farooq ${ }^{1}$, Muhammad Iqrar $^{2}$, Asghar khan $^{3}$, Laila \\ Ameer $^{4}$, Saira Shakoor ${ }^{5}$, Sehar Shahbaz ${ }^{6}$ \\ ${ }^{1}$ University Institute of Radiological Sciences \& Medical Imaging Technology, The University \\ of Lahore, Pakistan
}

\begin{abstract}
Background: Thyroid nodules (TNs) are among the common diseases of the endocrine system, with $3 \%-7 \%$ prevalence by palpation. The prevalence by high-resolution ultrasonography among randomly selected individuals is $19 \%-67 \%$, with annual increasing trends worldwide. $5 \%$ to $15 \%$ of TNs is thyroid cancer, which has become the fastest growing cancer. ${ }^{1}$ Ultrasonography has become an indispensable tool in the evaluation of thyroid nodular disease, and most patients will have had a thyroid ultrasound prior to initial surgical evaluation. ${ }^{9}$ Objective: To characterize thyroid nodules in various age groups and gender. Methodology: In this descriptive study, among 179 patients of thyroid nodule were selected with age and gender discrimination by convenient sampling, at Department of Radiology, Lahore General hospital and Inmol Cancer hospital Lahore. Mindray Z5 and Toshiba xario 100 with linear probe of $7.5-11 \mathrm{MHz}$ ultrasound machine was used. Results: Out of 179 collected, 105 were females and 74 were males who visited radiology department due to thyroid nodule. It shows $58.7 \%$ females and $41.3 \%$ males patients diagnosed. Out of 179 patients 106 patients $59.2 \%$ came with irregular margins thyroid nodules and remaining 73 patients $40.8 \%$ had thyroid nodules with regular margins. 127 patients $70.9 \%$ had hyperechoic thyroid nodules and 52 patients $29.1 \%$ had hypoechoic thyroid nodules. Out of 97 patients 54.2\% developed (Multi Nodular Goiter) MNG, 66 patients 36.9\% developed right thyroid nodules and 16 patients $8.9 \%$ developed left thyroid nodules. Females developed 56.2\% MNG, 33.3\% right thyroid nodule and $10.5 \%$ left thyroid nodule while males developed $51.4 \% \mathrm{MNG}, 41.9 \%$ right thyroid nodule and $6.8 \%$ left thyroid nodule. Out of 179 patients $109(60.9 \%)$ patients shows no perfusion of blood while remaining $70(30.1 \%)$ shows some perfusion of blood on USG. Minimum age was 5 years and maximum were 90 years while their mean was 43 . Age group between 41 to 50 years most likely develop thyroid nodules. Conclusion: In this study we conclude that females most likely develop thyroid nodules than males. Both males and females mostly develop multi nodular goiter and least develop left thyroid nodule. Patients in $4^{\text {th }}$ decade most likely develop thyroid nodules.
\end{abstract}

Key words: Thyroid nodules, Ultrasonography

DOI: $10.7176 / \mathrm{JHMN} / 80-15$

Publication date:September $30^{\text {th }} 2020$

\section{INTRODUCTION}

Thyroid nodules are among the common diseases of the endocrine system, with $3 \%-7 \%$ prevalence by palpation. The prevalence by high-resolution ultrasonography among randomly selected individuals is $19 \%-$ $67 \%$, with annual increasing trends worldwide. $5 \%$ to $15 \%$ of TNs is thyroid cancer, which has become the fastest growing cancer. The high prevalence of TNs may be partly because of the advancements in diagnostic technologies, but it still cannot be explained by traditional risk factors such as sex, age, iodine intake, and radiation exposure. Meanwhile, lifestyles have very important effects on obesity and metabolic syndrome. Unhealthy habits have sparked an epidemic of diseases that together constitute the leading cause of death globally, as reported by the World Health Organization. Therefore, it is imperative to investigate the effects of lifestyles on the prevalence of TNs. ${ }^{1}$ Excess weight and obesity have been associated with an increased risk of musculoskeletal disorders, hypertension, diabetes, cardiovascular disease, and metabolic syndrome. And they are also associated with a high risk of some common adult cancers, including thyroid cancer. Positive associations between height, weight and body mass index and thyroid cancer have been reported in large prospective studies and meta-analysis, but these associations generally have been weak and have not always been consistent across studies. $^{2}$ Thyroid hormones have a profound effect on energy homeostasis, lipid and glucose metabolism, and blood pressure. Therefore, it is hypothesized that functional changes in the thyroid gland might have an association with MetS and its related components including obesity, IR, lipid and glucose metabolism 
abnormalities, and raised blood pressure. Previous reports investigated functional and morphological alterations of the thyroid gland in relation to obesity. Dysregulated axis of the hypothalamus, pituitary, thyroid, and the adipose tissue was hypothesized as underlying pathophysiologic mechanisms. Although previous studies reported inconsistant thyroid functional changes, increased TSH levels in the subjects seemed to be a consistent finding. Contradictory findings of these reports might be related to the study design, in which the investigators included patients with different severity of obesity and iodine intake. Additionally, in a very recent report, increased thyroid volume and nodule prevalence were also reported in patients with IR in an iodine-sufficient area for the first time. ${ }^{3}$

Epidemiological studies have demonstrated a relatively high frequency of thyroid diseases, including thyroid nodules, among middle-aged females. Previous studies have found that $1.3-4 \%$ of malignancies presenting in the thyroid nodule are diagnosed using FNAC. During the last 15 years, popular use of thyroid ultrasound and improved detection rates with new high-resolution machines has increased the diagnostic rate of thyroid nodules. The presence of thyroid nodules in over $50 \%$ of the studied cohort is not unusual. In contrast, the incidence of thyroid cancer in histologically proven thyroid nodules is variable depending on the surgical indication at different centers. Increased incidences of thyroid cancer have been reported in recent years; this could be attributed to the application of thyroid ultrasound and histological reports on thyroid micro carcinoma. The incidence of thyroid cancer in thyroid nodules, as detected by thyroid ultrasound, was found to range from $7.9 \%$ to $32.7 \%$ depending on the selected population. ${ }^{4}$

Even though the relationship between radiation exposure and thyroid cancer is well known, many questions remain about the advisability of routine screening. This question is relevant to the large number of people exposed to radiation during childhood. This includes people exposed to external radiation for therapeutic purposes and those living in the area of radioactivity release, such as occurred after the Chornobyl accident. In fact, anyone born and residing in the United States before the end of above-ground nuclear testing was exposed to fallout. One of the central questions about screening is the use of thyroid ultrasound. The resolution of ultrasound has continued to improve, the dissemination of machines has continued to rise, and the size and cost of machines has continued to fall. However, concern about thyroid ultrasound arises because the large numbers of small thyroid nodules it detects are usually of little or no clinical importance, but may result in unneeded tests and procedures, and unnecessary anxiety. ${ }^{5}$ In the past, patients were irradiated for enlarged thymus, tonsils and adenoids, cervical lymphadenopathy from tuberculosis, cerebral tumors and benign skin conditions, including keloids, acne, birthmarks, and tinea capitis. Thousands of children were irradiated in the United States and other countries between the years 1920 to 1950. Approximate dosages ranged from 6 to 1500 rads. Although the administration of low dose therapeutic radiation for benign conditions is no longer performed, radiation is still used to treat patients with Hodgkin's disease, lymphomas, squamous cell carcinomas, and other tumors. Persons have also been exposed to radiation from fallout as a result of atomic bomb explosions and nuclear plant accidents. Patients are also currently being treated with radioiodine for Graves' disease, toxic nodular goiter, and other conditions. The development of thyroid cancers after radiation exposure may also differ from thyroid cancers that develop spontaneously. In the former, one can document the time between radiation exposure and the subsequent diagnosis and treatment of the thyroid nodule or nodules. ${ }^{6}$

Individuals treated for Hodgkin's disease during childhood and adolescence have an excellent prognosis, and the majority will go on to become long-term survivors. Abnormalities of the thyroid gland, including hypothyroidism, hyperthyroidism, and thyroid neoplasms, all have been reported to occur at a higher rate among HD survivors compared to the general population. ${ }^{7}$ In the United States, approximately 23,500 cases of differentiated thyroid cancer are diagnosed each year, and the yearly incidence may be increasing. In 1996, the American Thyroid Association (ATA) published treatment guidelines for patients with thyroid nodules and thyroid cancer. Over the last decade, there have been many advances in the diagnosis and therapy of both thyroid nodules and differentiated thyroid cancer. ${ }^{8}$ Ultrasonography has become an indispensable tool in the evaluation of thyroid nodular disease, and most patients will have had a thyroid ultrasound prior to initial surgical evaluation. ${ }^{9}$ Ultrasonography of the cervical region performed for reasons other than thyroid disease has shown that $13 \%$ to $88 \%$ of patients have thyroid nodules. Thyroid B-mode scans show typical nodule features such as the contour, dimensions, echogenicity, presence and type of peripheral halo, and number of nodules in up to $75 \%$ of patients; however, this diagnostic mode is not sufficiently specific to establish the nature of the nodule. Fineneedle aspiration biopsy (FNAB) is considered the most specific preoperative diagnostic method. Power Doppler scans performed with high-frequency transducers allow identification of low velocity blood flow in superficial tissues, such as the thyroid gland. ${ }^{10}$ Thyroid nodularity is common ageing process, most commonly seen in the elderly individuals. There is variation of thyroid nodules in males and females. But no satisfactory information is 
available in the literature regarding the incidence of thyroid nodule in various age groups and gender in our population.

\section{Method:}

In this descriptive study, among 179 patients of thyroid nodule were selected with age and gender discrimination by convenient sampling, at Department of Radiology, Lahore General hospital and Inmol Cancer hospital Lahore. Mindray Z5 and Toshiba xario 100 with linear probe of $7.5-11 \mathrm{MHz}$ ultrasound machine was used. Patients with clinical evidence of thyroid nodule were included in this study and un cooperative and patients with thyroidectomy were excluded in this study.

\section{RESULTS:}

Out of 179 collected, 105 were females and 74 were males who visited radiology department due to thyroid nodule. It shows $58.7 \%$ females and $41.3 \%$ males patients diagnosed. Out of 179 patients 106 patients $59.2 \%$ came with irregular margins thyroid nodules and remaining 73 patients $40.8 \%$ had thyroid nodules with regular margins. 127 patients $70.9 \%$ had hyperechoic thyroid nodules and 52 patients $29.1 \%$ had hypoechoic thyroid nodules. Out of 97 patients 54.2\% developed (Multi Nodular Goiter) MNG, 66 patients 36.9\% developed right thyroid nodules and 16 patients $8.9 \%$ developed left thyroid nodules. Females developed 56.2\% MNG, 33.3\% right thyroid nodule and $10.5 \%$ left thyroid nodule while males developed $51.4 \% \mathrm{MNG}, 41.9 \%$ right thyroid nodule and $6.8 \%$ left thyroid nodule. Out of 179 patients $109(60.9 \%)$ patients shows no perfusion of blood while remaining $70(30.1 \%)$ shows some perfusion of blood on USG. Minimum age was 5 years and maximum were 90 years while their mean was 43 . Age group between 41 to 50 years most likely develop thyroid nodules.

Table 1: Frequency distribution of Gender

\begin{tabular}{|rl|r|r|r|r|}
\hline & & & & \multicolumn{2}{c|}{$\begin{array}{c}\text { Cumulative } \\
\text { Percent }\end{array}$} \\
\hline Valid & F & 105 & 58.7 & 58.7 & 58.7 \\
& M & 74 & 41.3 & 41.3 & 100.0 \\
& Total & 179 & 100.0 & 100.0 & \\
\hline
\end{tabular}

Table 1 shows that $58.7 \%$ females and $41.3 \%$ males developed thyroid nodules. Females came with higher ratio of thyroid nodules.

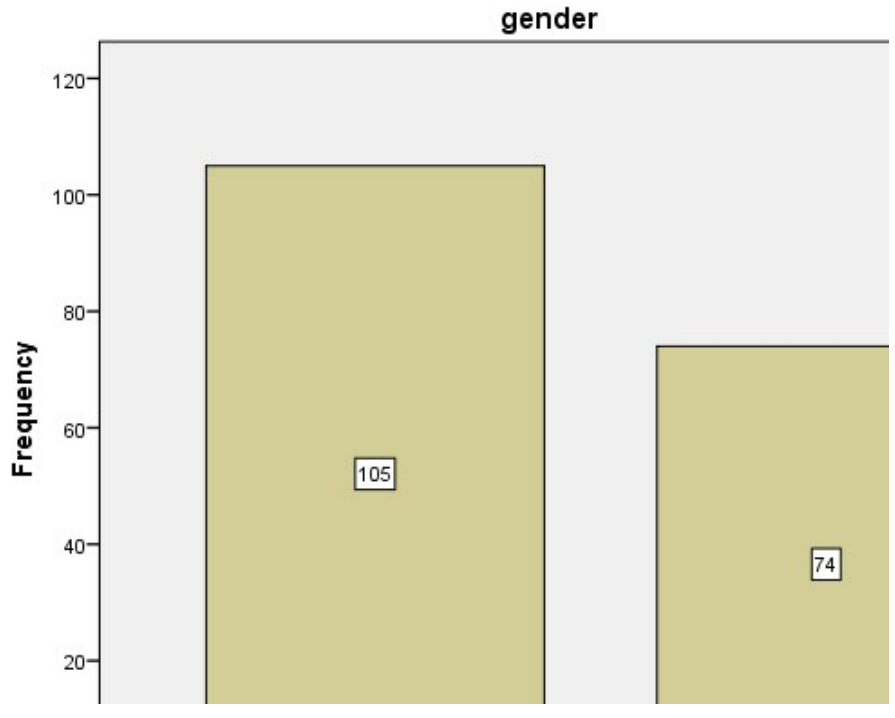

Graph 1: Frequency distribution of gender 
Table 2: Frequency distribution of Margins

\begin{tabular}{|ll|r|r|r|r|}
\hline & & & & \multicolumn{2}{c|}{$\begin{array}{c}\text { Cumulative } \\
\text { Percent }\end{array}$} \\
\hline Valid & IRREGULAR & 106 & 59.2 & 59.2 & 59.2 \\
& REGULAR & 73 & 40.8 & 40.8 & 100.0 \\
& Total & 179 & 100.0 & 100.0 & \\
\hline
\end{tabular}

Table shows 106 patients with thyroid nodules had irregular margins and 73 patients had regular margins.

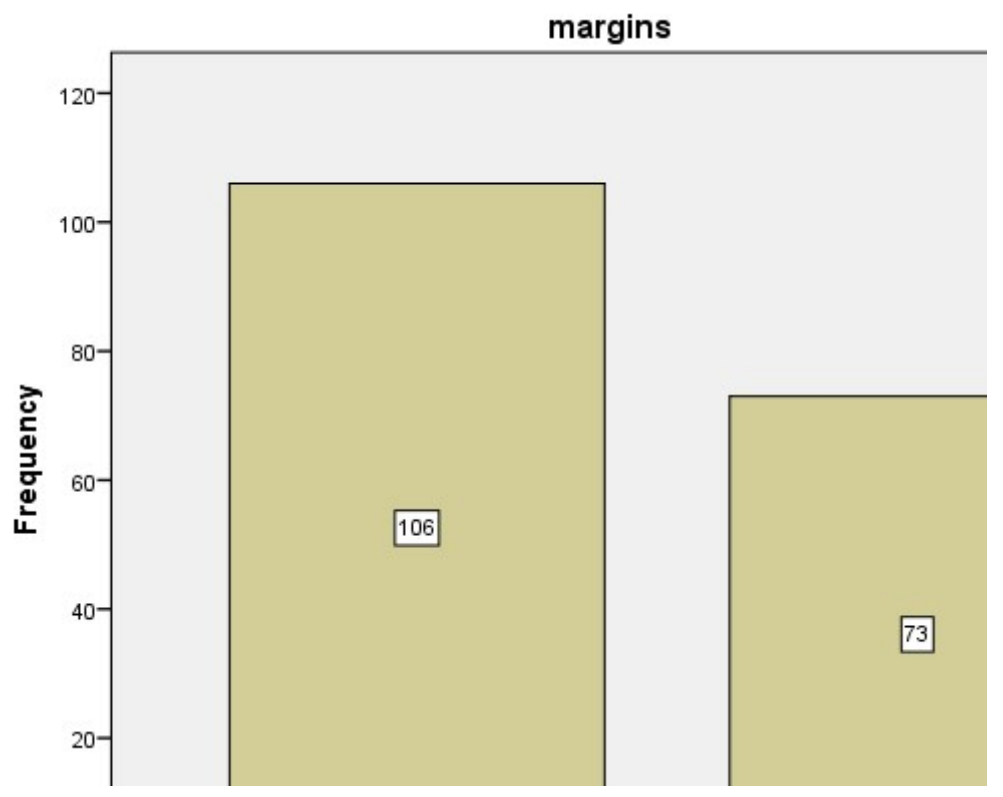

Graph 2: Frequency distribution of margins of thyroid nodules

Table 3: Frequency distribution of ECHOGENICITY

\begin{tabular}{|rl|r|r|r|r|}
\hline & & & & \multicolumn{2}{c|}{$\begin{array}{c}\text { Cumulative } \\
\text { Percent }\end{array}$} \\
\hline Valid & FYPERECHOIC & 127 & 70.9 & 70.9 & 70.9 \\
& HYPOECHOIC & 52 & 29.1 & 29.1 & 100.0 \\
& Total & 179 & 100.0 & 100.0 & \\
\hline
\end{tabular}

Table shows $70.9 \%$ patients with thyroid nodules had hyperechoic echogenicity and $29.1 \%$ had hypoechoic echogenicity of thyroid nodules. 


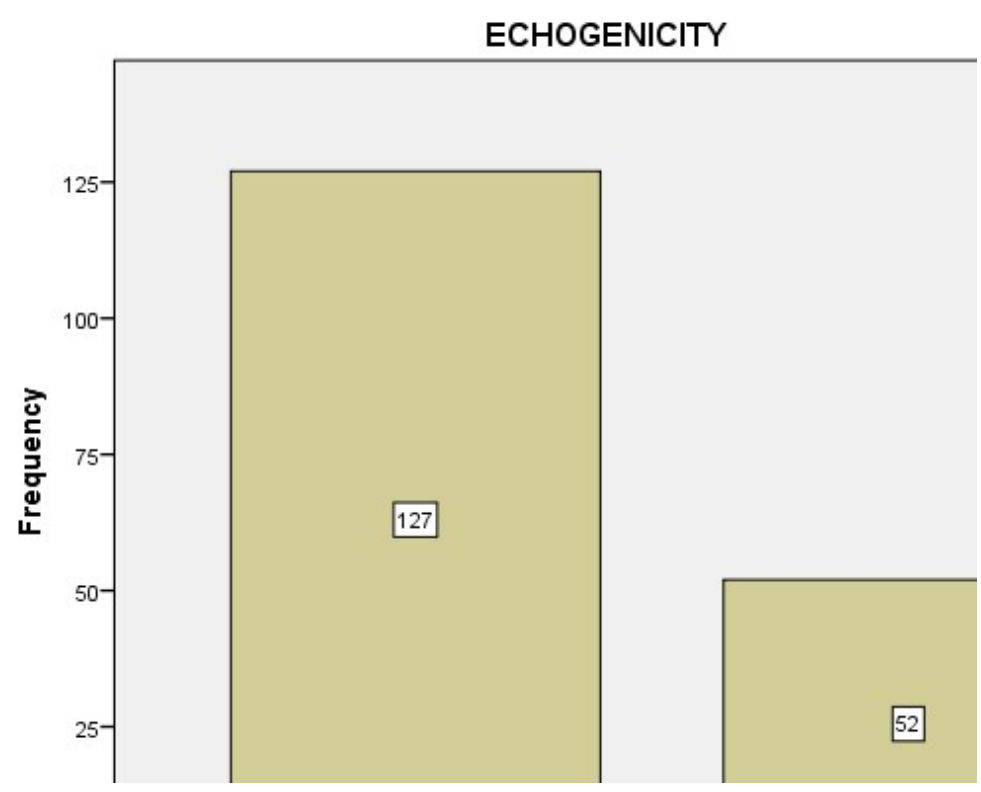

Graph 3: Frequency distribution of echogenicity of thyroid nodules

Table 4: Frequency distribution of Lesions

\begin{tabular}{|ll|r|r|r|r|}
\hline & & & & Cumulative \\
\hline Valid & FT THYROID NODULE & 16 & 8.9 & Percent \\
& MNG & 97 & 54.2 & 8.9 & 8.9 \\
RT THYROID NODULE & 66 & 36.9 & 54.2 & 63.1 \\
Total & 179 & 100.0 & 36.9 & 100.0 \\
\hline
\end{tabular}

Table shows 66 patients develop right thyroid nodule , 97 develop MNG and 16 patients develop left thyroid nodules. 


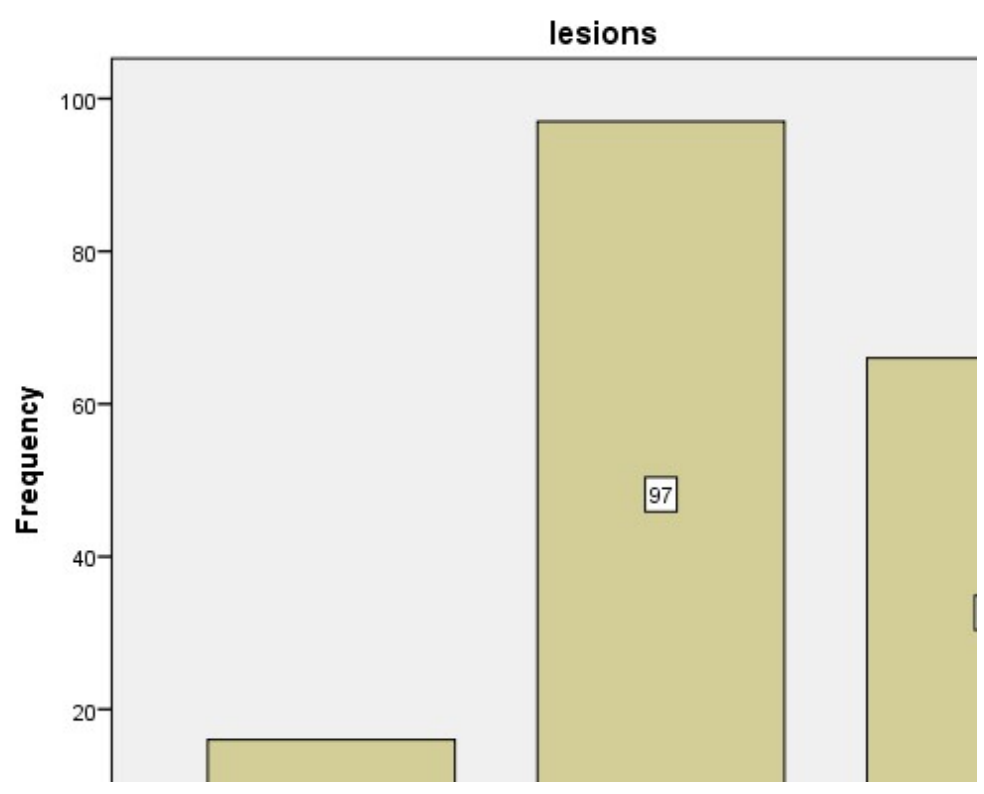

Graph 4: frequency distribution of lesions in thyroid nodules

Table 5: Frequency distribution of BLOOD FLOW PERFUSION

\begin{tabular}{|rl|r|r|r|r|}
\hline & & & & \multicolumn{2}{c|}{$\begin{array}{c}\text { Cumulative } \\
\text { Percent }\end{array}$} \\
\hline Valid & Frequency & Percent & Valid Percent & \multicolumn{2}{|c|}{ PERFUSION } \\
SOME PERFUSION & 109 & 60.9 & 60.9 & 39.1 & 100.0 \\
& 70 & 39.1 & 100.0 & \\
\hline
\end{tabular}

Table shows $60.9 \%$ of nodules shows no perfusion of blood and $39.1 \%$ shows some perfusion of blood.

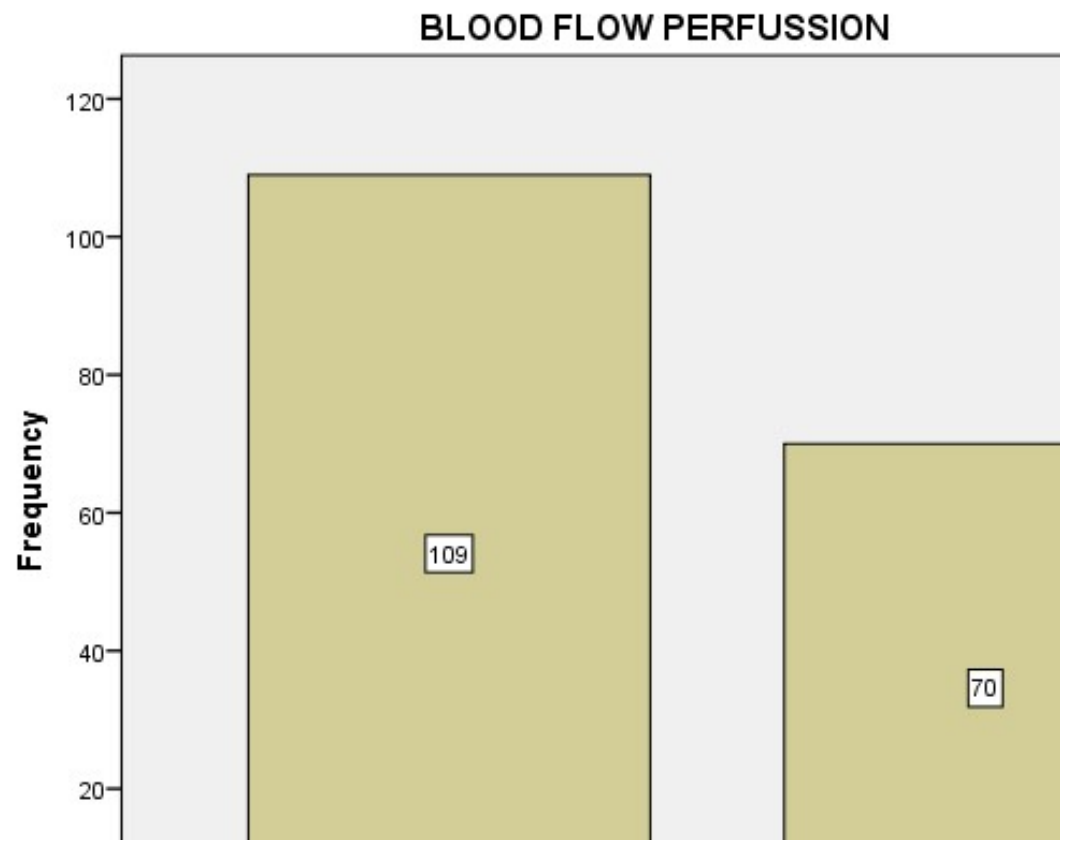

Graph 5: Frequency distribution of blood perfusion in thyroid nodule patients 
Table 6: Frequency distribution of Gender * Lesions Crosstabulation

\begin{tabular}{|c|c|c|c|c|c|c|}
\hline & \multicolumn{3}{|c|}{ Lesions } & \multirow[b]{2}{*}{ Total } \\
\hline & & & $\begin{array}{l}\text { LT THYROID } \\
\text { NODULE }\end{array}$ & $\mathrm{MNG}$ & $\begin{array}{l}\text { RT THYROID } \\
\text { NODULE }\end{array}$ & \\
\hline \multirow[t]{4}{*}{ Gender } & $\mathrm{F}$ & Count & 11 & 59 & 35 & 105 \\
\hline & & $\%$ within gender & $10.5 \%$ & $56.2 \%$ & $33.3 \%$ & $100.0 \%$ \\
\hline & M & Count & 5 & 38 & 31 & 74 \\
\hline & & $\%$ within gender & $6.8 \%$ & $51.4 \%$ & $41.9 \%$ & $100.0 \%$ \\
\hline \multirow[t]{2}{*}{ Total } & & Count & 16 & 97 & 66 & 179 \\
\hline & & $\%$ within gender & $8.9 \%$ & $54.2 \%$ & $36.9 \%$ & $100.0 \%$ \\
\hline
\end{tabular}

Table shows 11 females develop LT thyroid nodules, 59 females develop MNG and 35 females develop RT thyroid nodules. And 5 males develop LT thyroid nodules, 38 males develop MNG and 31 males develop RT thyroid nodules.

Table 7: Descriptive Statistics

\begin{tabular}{|l|r|r|r|r|r|}
\hline & \multicolumn{1}{|c|}{$\mathrm{N}$} & Minimum & Maximum & \multicolumn{1}{c|}{ Mean } & Std. Deviation \\
\hline Age & 179 & 5.00 & 90.00 & 43.0168 & 20.70702 \\
Valid N (listwise) & 179 & & & & \\
\hline
\end{tabular}

Table shows minimum age was 5 years and maximum age was 90 years.

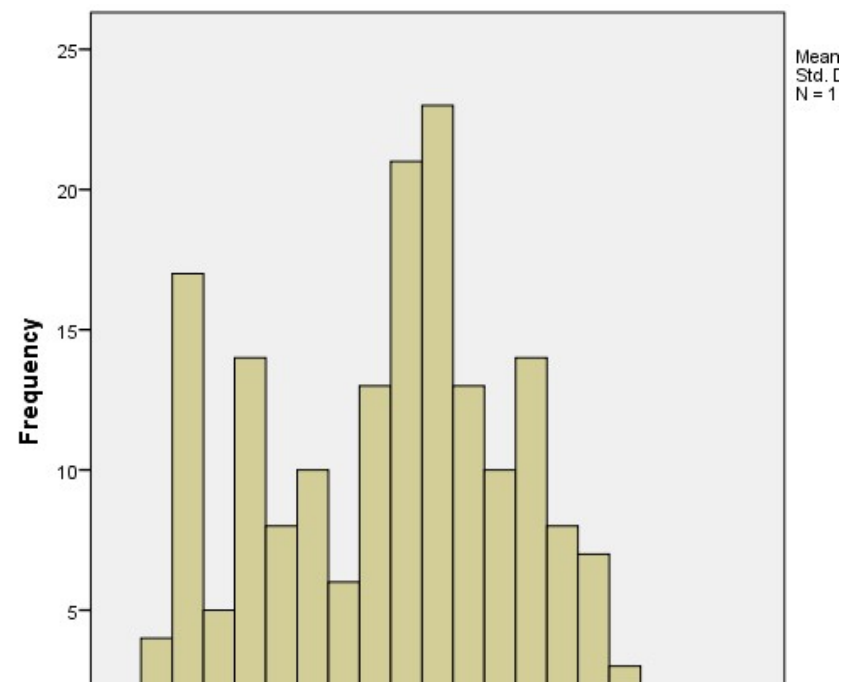

Graph 6: Age Statics

Table 7: Descriptive Statistics

\begin{tabular}{|l|r|r|r|r|r|}
\hline & \multicolumn{1}{|c|}{$\mathrm{N}$} & Minimum & Maximum & \multicolumn{1}{c|}{ Mean } & Std. Deviation \\
\hline RI & 179 & .30 & .90 & .5274 & .15020 \\
PI & 179 & .50 & 1.00 & .8391 & .11819 \\
SD & 179 & .40 & 9.20 & 4.2324 & 1.90310 \\
Valid N (listwise) & 179 & & & & \\
\hline
\end{tabular}

Table shows minimum RI in patients were 0.3 and maximum were 0.9 , and minimum PI were 0.5 and maximum were 1.0, and minimum SD were 0.4 and maximum SD were 9.20. 


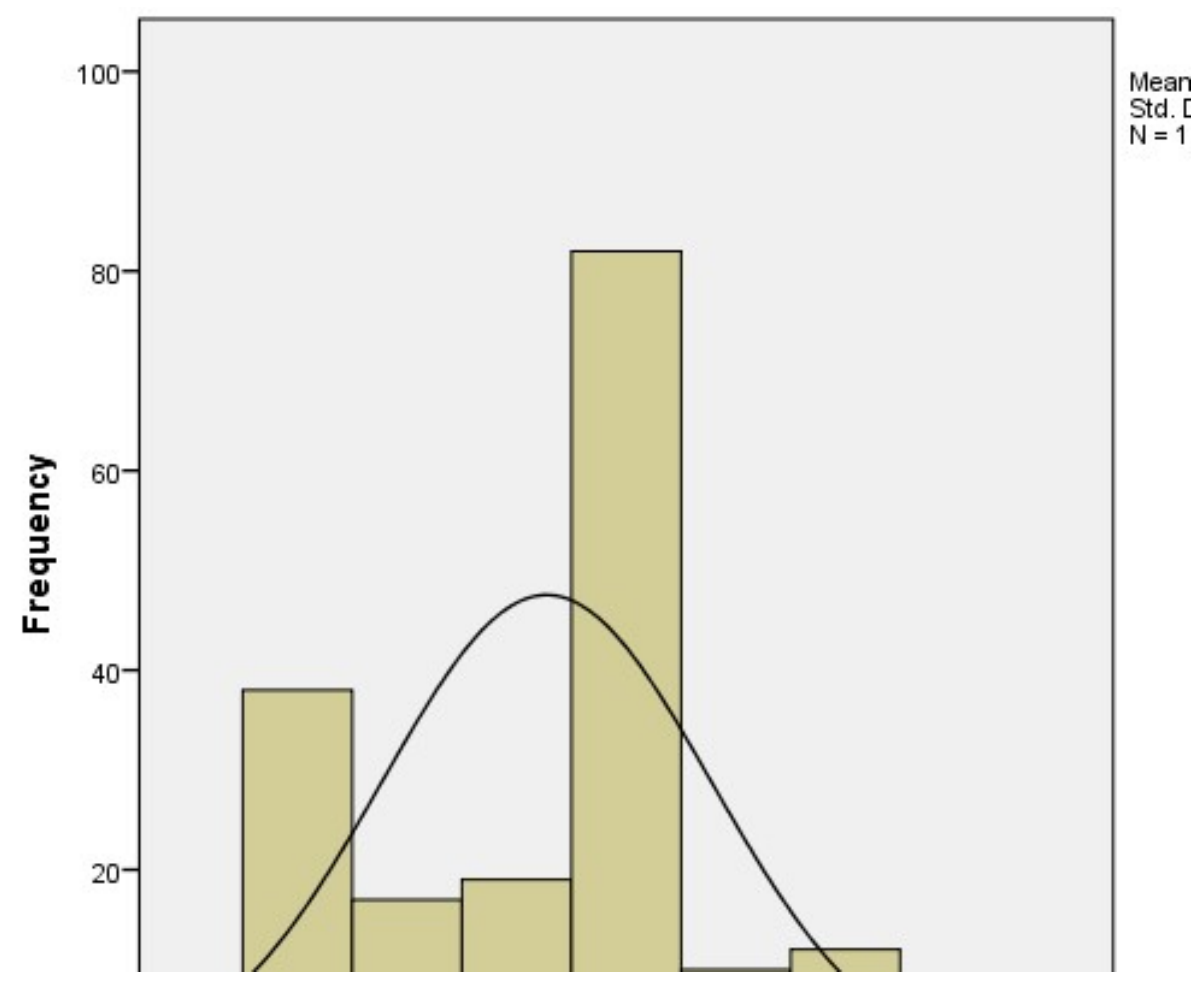

Graph 7: Resistivity Index

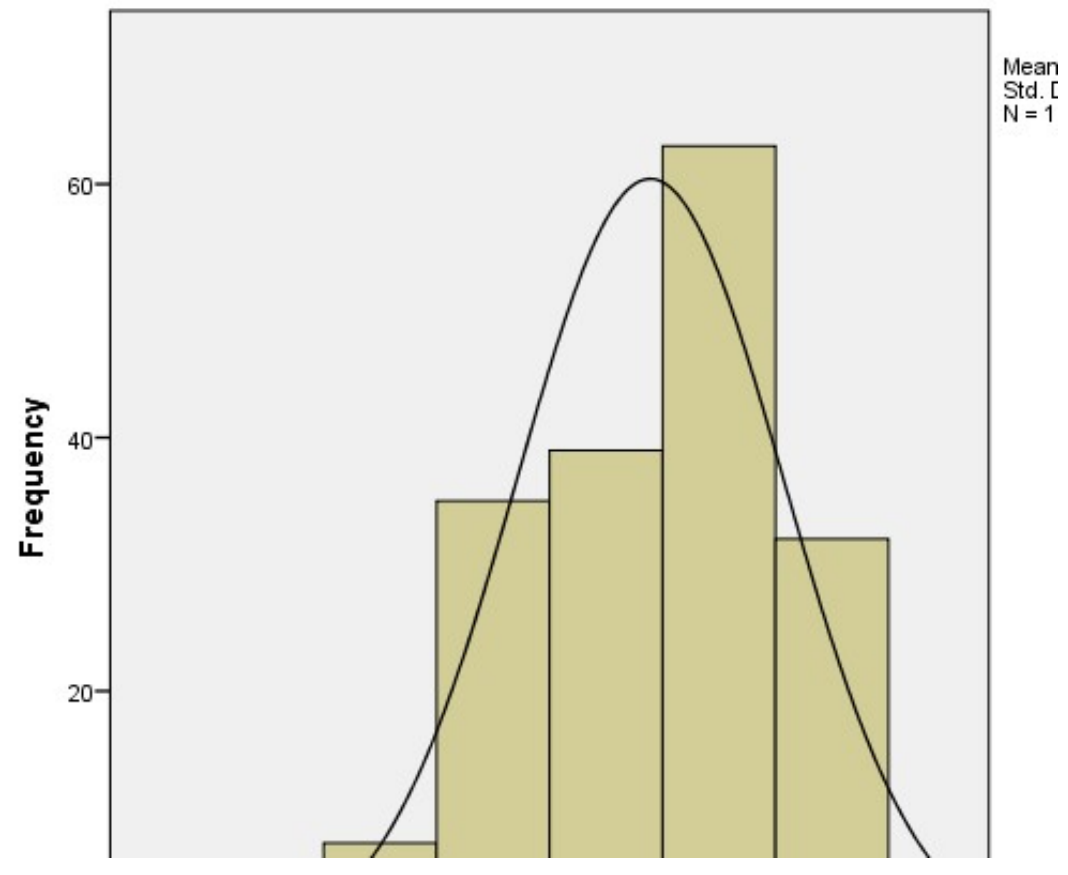

Graph 8: Palsuatility Index 


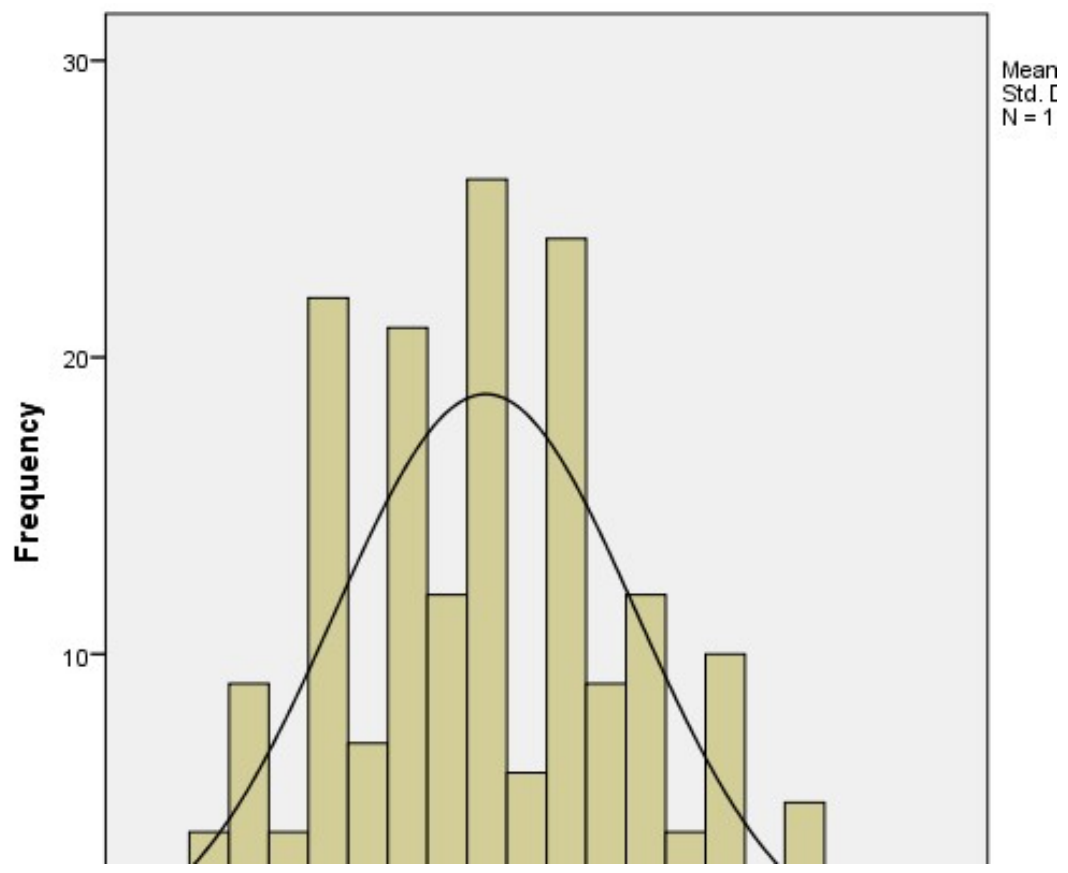

Graph 9: SD Ratio

\section{DISCUSSION:}

Out of 179 collected, 105 were females and 74 were males who visited radiology department due to thyroid nodule. It shows $58.7 \%$ females and $41.3 \%$ males patients diagnosed. Out of 179 patients 106 patients 59.2\% came with irregular margins thyroid nodules and remaining 73 patients $40.8 \%$ had thyroid nodules with regular margins. 127 patients $70.9 \%$ had hyperechoic thyroid nodules and 52 patients $29.1 \%$ had hypoechoic thyroid nodules. Out of 97 patients 54.2\% developed (Multi Nodular Goiter) MNG, 66 patients 36.9\% developed right thyroid nodules and 16 patients 8.9\% developed left thyroid nodules. Females developed 56.2\% MNG, 33.3\% right thyroid nodule and $10.5 \%$ left thyroid nodule while males developed $51.4 \% \mathrm{MNG}, 41.9 \%$ right thyroid nodule and $6.8 \%$ left thyroid nodule. Out of 179 patients $109(60.9 \%)$ patients shows no perfusion of blood while remaining $70(30.1 \%)$ shows some perfusion of blood on USG. Chen et al. announced the predominance of TNs among people was $24.1 \%$ and $34.7 \%$ in Hangzhou, a city of eastern China in 2013. The commonness among individuals matured more than 40 years of age in Nanjing had arrived at $46.6 \%$ in 2014. An aggregate of 6324 subjects took an interest right now. The segment information are appeared in Table 1. Age, weight file level of smokers, and level of liquor consumers among female subjects were altogether lower contrasted with male subjects Among the 6324 cases researched, 3100 subjects had TNs. The general predominance rate was 49\%; after institutionalization by age, pervasiveness got $40.1 \%$. Seventy-three patients had experienced careful resection for TNs, and 57 patients backslid. The commonness of TNs was altogether higher in females contrasted with guys There were 1099 instances of singular knobs, representing 35.5\%. Various knobs represented 59.2\% in guys and $67.0 \%$ in females. The pervasiveness paces of TNs were $25.8 \%, 32.4 \%, 42.0 \%, 51.9 \%, 59.4 \%, 65.5 \%$, and $73.7 \%$ in the under $30,30-39,40-49,50-59,60-69,70-79$, and multi year-old or more gatherings, individually. Pervasiveness rates expanded fundamentally as age expanded, and the Cochran-Armitage pattern test was additionally factually noteworthy It was the equivalent for the two guys and females The pervasiveness of TNs was $43.7 \%$ in male current smokers, $42.1 \%$ in male previous smokers, and $40.3 \%$ in male non-smokers, with no huge contrast among the gatherings .The predominance in female current smokers and previous smokers was $61.4 \%$ and $64.4 \%$, separately, which was altogether higher than the $51.9 \%$ in female non-smokers. There was no huge contrast in the predominance of TNs among the present consumers, previous consumers, and nonconsumers in either guys or females. People devouring iodized salt were $99.7 \%$. The predominance of TNs was $48.6 \%, 49.4 \%$, and $48.8 \%$ in the salty, normal, and less salty salt inclination gatherings, separately. The commonness of TNs in various gatherings had no factual contrast .The predominance of TNs was $46.1 \%$ in the gathering with visit fish consumption, $48.5 \%$ in the gathering with periodic admission, and $52.4 \%$ in those with no fish admission. The distinctions in predominance among these gatherings were measurably noteworthy .Additionally, with expanded recurrence of fish consumption, TN predominance diminished, and the Cochran- 
Armitage pattern test brought about factual essentialness. The investigation of the physical work force indicated that the light difficult work bunch had the most elevated commonness of TNs with $50.5 \%$, trailed by the light physical work bunch with $45.4 \%$, the moderate work bunch with $43.1 \%$, lastly the substantial work bunch with $25.0 \%$. The pervasiveness of TNs among various physical work bunches contrasted essentially. Along these lines, with the abatement in physical work force, nodular predominance altogether expanded, appeared by the Cochran-Armitage pattern test .The commonness of TNs in the mellow physical exercise power bunch was the most elevated with $49.6 \%$, trailed by the moderate force physical exercise bunch with $47.5 \%$, lastly the high power physical exercise bunch with $34.4 \%$, which was the least. ${ }^{1}$ Another examination was led by Oktay Algin, MD et.al, seventy seven thyroid knobs were contemplated in 60 back to back patients at our establishment from July 2007 to December 2008. The patients went in age from 20 to 70 years .Composed educated assent from each subject was acquired and the morals board of trustees at our establishment endorsed the methods of this examination. Mean patient age was $49.5 \pm 9.7$ and $49.3 \pm 13.2$ years in patients with considerate and threatening knobs, individually. Generally speaking knob breadth went from $10-42 \mathrm{~mm}$ in the best measurement Cytoobsessive outcomes were comparable in both genders and diverse age gatherings .Co-dreary illnesses were hypertension type 2 diabetes mellitus and coronary supply route infection .Pressure side effects, for example, dryness or inconvenience gulping were obvious in 12 patients. Thyroid capacity tests were ordinary in 59 of 60 patients; subclinical hypothyroidism was analyzed in one patient. Discoveries Upon physical assessment of 77 knobs, 24 knobs were seen as hard, 24 were resolved to be delicate, and 29 were non-tangible. These 29 knobs were just observable under US assessment. None of the knobs were fixed or excruciating. In one case, cervical adenopathy was perceived and FNAB of the knob and adenopathy both uncovered metastatic adenocarcinoma. Correlation of cytopathologic and physical assessment discoveries uncovered that the recurrence of hard knobs in the threatening gathering was fundamentally higher contrasted with the favorable gathering. ${ }^{11} \mathrm{C}$ SHI et.al directed an examination right now patients conceded for thyroid medical procedure to The Second Subsidiary Emergency clinic of Harbin Clinical College, Harbin, China, between January 2005 and January 2010 were remembered for the investigation. An aggregate of 4186 patients matured somewhere in the range of 18 and 76 years conceded for thyroid medical procedure were remembered for the examination. Of these, 648 were male and 3538 were female .Thyroid maladies analyzed at medical procedure included thyroid carcinoma, nodular goiter, thyroid adenoma, Hashimoto's thyroiditis, hyperthyroidism and subacute thyroiditis. The occurrences of microcalcifications and macrocalcifications in benevolent and harmful thyroid illness are outlined in Table 1. There were 1391 harmful cases and 2795 considerate cases Positive calcification signs were seen during preoperative ultrasound assessment in an aggregate of 1725 patients; of these, 916 cases were dangerous and 809 cases were kindhearted. The frequency of threat was $96.5 \%$ for patients with miniaturized scale calcifications and $41.1 \%$ for patients with macrocalcifications. Of the 1725 patients with calcifications, 659 demonstrated a solitary nodular region of calcification; of these, 193 were benevolent and 466 were threatening. The staying 1066 patients had different nodular calcifications; of these, 543 were generous and 523 were threatening. The frequency of danger was fundamentally higher in patients with single nodular calcification than in those with various calcifications. $^{12}$

\section{Conclusion:}

In this study we conclude that females most likely develop thyroid nodules than males. Both males and females mostly develop multi nodular goiter and least develop left thyroid nodule. Patients in $4^{\text {th }}$ decade most likely develop thyroid nodules.

\section{REFRENCES}

1. Jiang H, Tian Y, Yan W, Kong Y, Wang H, Wang A, Dou J, Liang P, Mu Y. The prevalence of thyroid nodules and an analysis of related lifestyle factors in Beijing communities. International journal of environmental research and public health. 2016 Apr;13(4):442.

2. Kim JY, Jung EJ, Park ST, Jeong SH, Jeong CY, Ju YT, Lee YJ, Hong SC, Choi SK, Ha WS. Body size and thyroid nodules in healthy Korean population. Journal of the Korean Surgical Society. 2012 Jan1; 82(1):137.

3. Ayturk S, GursoyA, KutA, Anil C, Nar A, Tutuncu NB. Metabolic syndrome and its components are associated with increased thyroid volume and nodule prevalence in a mild-to-moderate iodine-deficient area. European Journal of Endocrinology. 2009 Oct1;161(4):599-605. 
4. Lin JD. Thyroid cancer in thyroid nodules diagnosed using ultrasonography and fine needle aspiration cytology. Journal of Medical Ultrasound. 2010 Jan 1;18(3):91-104.

5. Mihailescu DV, Collins BJ, Wilbur A, Malkin J, Schneider AB. Ultrasound-detected thyroid nodules in radiation-exposed patients: changes over time. Thyroid. 2005 Feb1;15(2):127-33.

6. Kikuchi S, Perrier ND, Ituarte P, Siperstein AE, Duh QY, Clark OH. Latency period of thyroid neoplasia after radiation exposure. Annals of surgery. 2004 Apr;239(4):536.

7. Sklar C, Whitton J, MertensA, et al. Abnormalities of the thyroid in survivors of Hodgkin's disease: data from the Childhood Cancer Survivor Study. J ClinEndocrinolMetab2000;85:3227-32

8. Smith BR, Cooper DS, Doherty GM, Haugen BR, Kloos RT, Lee SL, Mandel SJ, Mazzaferri EL, McIver B, Sherman SI, Tuttle RM. Management guidelines for patients with thyroid nodules and differentiated thyroid cancer. Thyroid. 2006 Feb 1;16(2):109-+.

9. Fukunari N, Nagahama M, SuginoK, Mimura T, Ito K, Ito K. Clinical evaluation of color Doppler imaging for the differential diagnosis of thyroid follicular lesions. World journal of surgery. 2004 Dec1;28(12):1261-5.

10. Chammas MC, GerhardR, OliveiraIR, WidmanA, BarrosND, DurazzoM, FerrazA, CerriGG. Thyroid nodules: evaluation with power Doppler and duplex Doppler ultrasound. Otolaryngology-Head and Neck Surgery. 2005Jun;132(6):874-82.

11. Algin O, Algin E, Gokalp G, Ocakoğlu G, Erdoğan C, Saraydaroglu O, Tuncel E. Role of duplex power Doppler ultrasound in differentiation between malignant and benign thyroid nodules. Korean journal of radiology. 2010 Dec1;11(6):594-602.

12. Lee HK, Hur MH, Ahn SM. Diagnosis of occult thyroid carcinoma by ultrasonography. Yonsei Medical Journal. 2003 Dec1;44(6):1040-4. 